\title{
Erosion of genetic resources within seed genebanks: the role of seed containers
}

\author{
César Gómez-Campo* \\ Escuela T. S. de Ingenieros Agrónomos, Universidad Politécnica de Madrid, E-28040 Madrid, Spain
}

For plant species with orthodox seeds, seed banks provide the most practical method for preserving large amounts of genetic material in a small space. The ultimate goal is seed preservation for several centuries, or perhaps even millennia. Paradoxically, seed banking practices can induce high levels of internal genetic erosion, starting with the sampling process and following through all the remaining processes: initial or periodic germination tests, distribution, regeneration, etc. These may appear quite normal and necessary operations, but they may also lead to a potentially significant waste of material when conducted without sufficient attention to detail, or without a minimal sense of economy. Defective seed preservation methods have been, by far, the main cause of massive losses of valuable material, and thus of genetic erosion.

The first seed bank in the world was created in St. Petersburg (Petrograd at that time, soon after renamed Leningrad, in the former USSR) in the 1920s. It was intended initially to preserve the important material collected by N.I. Vavilov during c. 100 collecting missions in 64 countries (Anonymous, 2006). However, such a glorious start was soon overshadowed by political and financial problems, which lasted a long time. During the Second World War, the Institut für Pflanzengenetik und Kulturpflanzenforschung (IPK) and its genebank were created within the Leibniz Institute in Gatersleben (Germany). With ups and downs during the war and post-war period, this bank actively functioned within the former DDR, and has recently celebrated its sixtieth anniversary. In the 1950s, a third large seed bank was established in Fort Collins (Colorado, USA) by the USDA National Seed Storage

*Correspondence

Email: gomezcampo@terra.es
Laboratory. The number of seed accessions stored in these three banks is enormous, well above 1 million.

However, none of these three large historical banks has ever claimed any encouraging germination results after storage periods of at least $40-50$ years. If some of the oldest accessions belonging to the Vavilov Institute have persisted to this day, it is mainly because they have been regenerated in the meantime. As far as is known, the IPK has only published germination results for accessions stored for shorter periods of time (Specht et al., 1998). In turn, germination results recently published by the USDA bank, on a set of species preserved for approximately 30-50 years, show how most accessions are now approaching their mid-life (Walters et al., 2005). In contrast to any theoretical prediction (Harrington, 1972), most genebank accessions stored during approximately half a century seem to be in an advanced stage of deterioration now - excepting particular cases of naturally long-lived seeds such as those of many legumes, etc.

In my opinion, the main reason for the failure to maintain high germination rates is the widespread use of inadequate containers, which allow water vapour to enter after some time (e.g. glass flasks with twist-off or screw lids, unsealed metal cans, plastic containers of different kinds, foil bags, etc.) (Gómez-Campo, 2002). In this research, 36 out of 40 containers tested $(90 \%)$ were unable to prevent water vapour uptake over a period of 3 years, and 13 out of 17 collaborating banks (c. $75 \%$ ) were using inadequate containers. In visits to at least 25 other seed banks in the past few years, I found a similar proportion using inadequate containers. Under such conditions it is impossible to maintain the necessary low moisture contents in the seeds, because these reach equilibrium with the high relative humidity that prevails in any uncontrolled cold room. This clearly illustrates the main cause of the present 
situation. In short, containers that are good for preserving cold drinks or potato crisps for a few months have been mistakenly judged adequate to preserve highly hygroscopic dry seeds for decades. As a second reason for this failure, emphasis has often been placed on low temperatures $(-5$ or $-10^{\circ} \mathrm{C}$, and often $-20^{\circ} \mathrm{C}$ ), rather than on the moisture content itself. The recommended figures are c. $3-7 \%$ of seed moisture (FAO/IPGRI, 1994). Ultra-drying of orthodox seeds, i.e. desiccation to values of seed moisture $<3 \%$, has rarely been used. Physiologists working at Reading University, UK (Ellis, 1998) have defended this procedure against claims that it might be harmful to the seeds (Walters and Engels, 1998). Unfortunately, seed ageing and longevity have mainly been studied indirectly, either through accelerated ageing or through supposed correlations with physico-chemical parameters.

In the mid-1960s, FAO (the Food and Agriculture Organization of the United Nations) issued a set of recommendations encouraging the establishment of a world net of seed banks, with the goal of preserving the high diversity of crop species lost by 'in situ' genetic erosion all around the world. The seed banks of Los Baños (Philippines), CYMMIT (Mexico), Hiratsuka (Japan) and Izmir (Turkey) were created within that decade to meet FAO recommendations.

In 1966, a small seed bank to preserve wild species initially crucifers and later endangered species in general - was created within the UPM (Universidad Politécnica de Madrid, Spain). For the first time, silica gel was included with the seeds in flame-sealed glass vials. Within this vapour-proof enclosure, silica gel maintains indefinitely ultra-dry levels of seed moisture $(1.5-3 \%)$, provides a second preservation mechanism by absorbing toxic gases produced during seed ageing (Lee et al., 2001) and warns - by changing its colour - if water vapour enters accidentally. The germination rates recorded after almost 40 years of storage are still very close to $100 \%$ (Pérez-García et al., 2007). For many years, no crop seed bank followed this procedure, probably because glass vials were considered to provide too small a volume for many types of crop seeds.

By 1969-70, crop genebanks were created in Bari (Italy), Castelar (Argentina) and Braunchweig (BRD), the latter recently merged with the Gatersleben bank. In 1973, a second bank devoted to wild species was established in connection with the Royal Botanic Gardens (Kew, UK). In 1974, Brasil's EMBRAPA opened the first bank of the network that was later developed there.

In 1974, the IBPGR (International Board of Plant Genetic Resources) was established by the CGIAR (Consultative Group on International Agricultural Research) as a body devoted to the conservation and use of plant genetic resources. Sixteen years later, it became an institute and was renamed IPGRI. At present, it maintains 22 offices around the world, which organize or support many collecting missions, panels, meetings, courses, etc., as well as promoting many other activities and connecting people around the world. However, its policies and recommendations regarding seed preservation were largely inspired by the previous experience of the three large historical seed banks, and these guidelines have been subsequently adopted by a large proportion of banks. Although the need for vapour-proof containers has often been emphasized, this message has clearly not reached all the prospective users. In fact, the ideas about the actual performance of containers have been confused, and each individual bank has decided, inconsistently, upon the selection. Considerable numbers of the world's seed banks seem to have made the wrong choice, because they are either regenerating their material prematurely or already concerned about the need to regenerate.

Later in the 1970s, several other banks were established. Among them was the National Bureau of Plant Genetic Resources (NBPGR, India 1976). Two banks created in 1979, the INIA (National Institute for Agricultural Research) genebank of Alcalá de Henares (Spain) and the Nordic Genebank of Alnarp (Sweden), are noteworthy because, at least in part, they both use hermetic containers for their base collections, and can therefore expect good longevities for their accessions.

In the 1980s, a network of seed banks devoted to wild species - mainly associated with botanical gardens - started to develop in the Iberian Peninsula, using the preservation methods set by the UPM bank of Madrid. Those in Córdoba and Las Palmas were the first to be established, and the network has grown steadily to consist of ten banks at present. In other countries, the number of banks using silica gel is also growing. At least the banks of Berlin-Dahlem in Germany, Porquerolles in France and Palermo in Italy have been storing their seeds with silica gel for a decade or more.

The decades of 1980s and 1990s witnessed a boom of crop seed banks created all around the world. Simultaneously, some large countries, such as Japan and China, created integrated systems to coordinate previous national efforts - NIAR (National Institutes of Agrobiological Resources) and the NGBC (National Gene Bank), respectively. Other countries have used institutions already established for this same purpose, e.g. EMBRAPA/CENARGEN in Brasil, or CYMMIT in Mexico. The total number of existing genebanks has recently been estimated at 1300 , with more than 6 million accessions, but these figures include non-seed genebanks (living collections, tissue culture collections and DNA banks). 


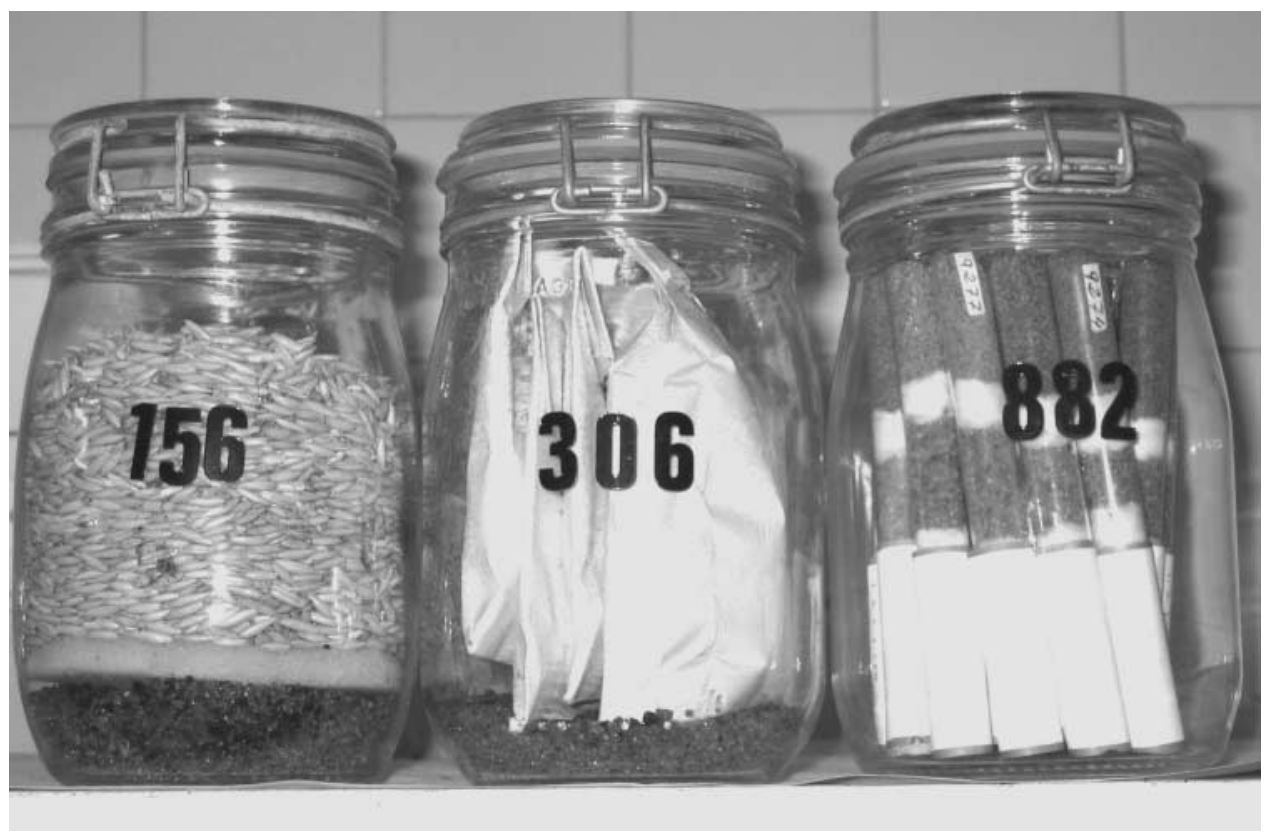

Figure 1. By using Kilner (Scotch) jars with silica gel in the bottom, seeds can be stored in bulk (left) or within any type of smaller container, e.g. paper, foil or polyvinyl bags (centre). Silica gel could also be placed in a transparent bag. In any case, seed moisture should previously be equilibrated with silica gel. Any of these procedures might also be used to minimize further ageing of poorly preserved accessions. When the same jars are used to store flame-sealed glass vials (right) no additional silica gel is needed, and a double $100 \%$ safety device is provided.

Unfortunately, the crop seed preservation methods of the past 25 years have shown few signs of overcoming their past deficiencies. The wording of recommendations such as to perform periodic germination tests every 5-10 years' or 'to perform regeneration when germination rates drop below $85 \%$ ' is much in line with a widespread pessimistic approach, leading many managers to become sceptical of the very possibility of preserving viable seeds over long periods. However, if seed accessions can really be stored to live 40-50 years without significant losses in viability, then germination tests carried out too frequently become largely meaningless, and the concerns about the need for regeneration should be reserved for a more distant future.

The UPM germination results provide solid hope for the possibility of efficient preservation of seeds over long periods. The above-mentioned UPM-based experimental research on seed containers (GómezCampo, 2002) tried to find valid alternatives for larger sized crop accessions. The most practical solution for applying the silica gel method to crop species might consist of using Kilner (Scotch) jars with rubber seals in the lid and silica gel in the bottom (Fig. 1). Further research is needed to find other alternatives. However, while a permeable container can be detected in a relatively short period of time - a few months or less - making sure that a container is safely vapour-proof might require several years.

\section{References}

Anonymous (2006) Vavilov, Nikolai Ivanovich. The Columbia encyclopedia (6th edition). New York, Columbia University Press.

Ellis, R.H. (1998) Longevity of seeds stored hermetically at low moisture contents. Seed Science Research 8 (suppl. 1), 9-10.

FAO/IPGRI (1994) Genebank standards. Rome, Food and Agriculture Organization of the United Nations/ International Plant Genetic Resources Institute.

Gómez-Campo, C. (2002) Long term seed preservation: the risk of using inadequate containers is very high. Monographs ETSIA, Universidad Politécnica de Madrid 163, 1-10. Available at http://www.seedcontainers.net

Harrington, J.F. (1972) Seed storage and longevity. pp. 145-245 in Kozlowsli, T.T. (Ed.) Seed biology. Volume 3. Insects, and seed collection, storage, testing and certification. New York, Academic Press.

Lee, P.-C., Taylor, A.G., Zhang, M. and Esashi, Y. (2001) Evolution of volatiles during seed aging: exogenous gas application. Journal of New Seeds 2, 77-91.

Pérez-García, F., González-Benito, M.E. and GómezCampo, C. (2007) High viability recorded in ultra-dry 
seeds of 37 species of Brassicaceae after almost 40 years of storage. Seed Science and Technology (in press).

Specht, C.-E., Freytag, U., Hammer, K. and Börner, A. (1998) Survey of seed germinability after long-term storage in the Gatersleben genebank (part 2). Plant Genetic Resources Newsletter 115, 39-43.

Walters, C. and Engels, J. (1998) The effects of storing seeds under extremely dry conditions. Seed Science Research 8 (suppl. 1), 3-8.
Walters, C., Wheeler, L.M. and Grotenhuis, J.M. (2005) Longevity of seeds stored in a genebank: species characteristics. Seed Science Research 15, 1-20.

Received 11 January 2006 accepted after revision 3 September 2006 (C) 2006 Cambridge University Press 